\title{
Lumbar tap-induced subarachnoid hemorrhage in a case of spinal epidural arteriovenous fistula
}

\author{
Takumi Kajitani, MD, ${ }^{1}$ Toshiki Endo, MD, PhD, ${ }^{1,2}$ Tomoo Inoue, MD, PhD, ${ }^{1}$ Kenichi Sato, MD, PhD, ${ }^{3}$ \\ Yasushi Matsumoto, MD, ${ }^{3}$ and Teiji Tominaga, MD, PhD'
}

\begin{abstract}
1Department of Neurosurgery, Tohoku University, Graduate School of Medicine, Sendai, Miyagi; and Departments of ${ }^{2}$ Neurosurgery and ${ }^{3}$ Neuroendovascular Therapy, Kohnan Hospital, Sendai, Miyagi, Japan
\end{abstract}

\begin{abstract}
The authors report the case of a 70-year-old woman with lumbar spinal epidural arteriovenous fistula (SEDAVF) who experienced subarachnoid hemorrhage (SAH) after a diagnostic lumbar puncture. According to the literature, perimedullary spinal vein enlargement is a hallmark of spinal vascular diseases; however, there are certain cases in which routine sagittal MRI fails to disclose signal flow voids. In such cases, patients may undergo a lumbar tap to investigate the possible causes of spinal inflammatory or demyelinating disease. Recognizing this phenomenon is essential because lumbar puncture of the epidural venous pouch or an enlarged intradural vein in SEDAVF may induce severe SAH. A high clinical index of suspicion can prevent similar cases in lumbar SEDAVF.

https://thejns.org/doi/abs/10.3171/2018.3.SPINE171343
\end{abstract}

KEYWORDS lumbar tap; subarachnoid hemorrhage; spinal epidural AVF; vascular disorders

$\mathrm{S}$ PINAL epidural arteriovenous fistula (SEDAVF) is a rare vascular malformation involving fistulas in the epidural space and is anatomically distinct from a typical spinal arteriovenous fistula (AVF). ${ }^{2-4,18,38}$ There are 2 subtypes of SEDAVF: epidural AVF with retrograde parenchymal drainage (type A) and pure epidural AVF (type B). ${ }^{16,35}$ In the former subtype, venous drainage from the fistula ascends into the dural sac; therefore, these patients experience progressive myelopathy ${ }^{29}$ Intradural signal flow voids and T2 hyperintensity in the spinal cord are hallmarks of type A SEDAVF, as observed on MRI; however, in certain cases of type A lumbosacral SEDAVFs, the epidural venous pouch is small, and an intradural flow void is inconspicuous, which could lead to delayed diagnosis. Here, we report the case of a type A lumbar SEDAVF in which the patient experienced severe subarachnoid hemorrhage (SAH) after a diagnostic lumbar puncture. Lumbar puncture was indicated in this specific case because thoracic and lumbar MRI could not detect signal flow voids, while abnormally high-intensity areas in the spinal cord were apparent on T2-weighted images. Preoperative eval- uations and a high clinical index of could possibly prevent this unusual and devastating sequela.

\section{Case Report}

A 70-year-old woman presented to an outside hospital with walking difficulty and a tingling sensation in her bilateral lower extremities. T2-weighted sagittal MRI revealed hyperintense thoracic spinal cord areas extending from $\mathrm{T} 8$ to the conus medullaris (Fig. 1). As perimedullary flow voids and epidural venous pouches were undetected, the patient underwent a diagnostic lumbar puncture. Severe headache and back pain immediately occurred after the lumbar puncture at L3-4. After intracranial SAH was detected on a head CT scan, the patient was referred to our hospital 2 weeks after the lumbar puncture. At our hospital, MRI of the head failed to detect any vascular pathology that could possibly explain SAH; rather, thoracolumbar T1-weighted MRI detected high-intensity areas at L3 (Fig. 2) that were compatible with the SAH source. T2weighted MRI showed the hematoma as a low-intensity 

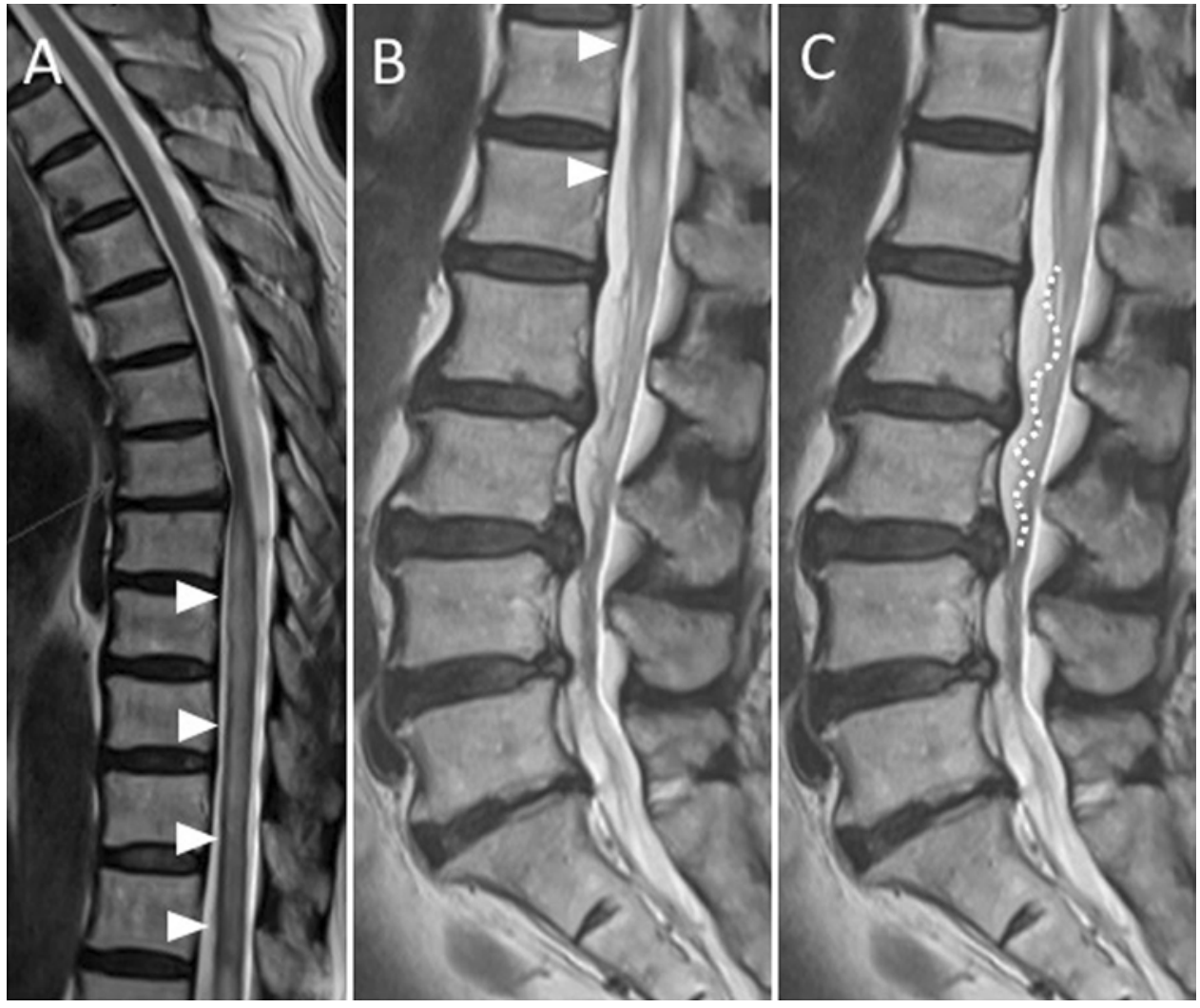

FIG. 1. Thoracic $(A)$ and lumbar $(B$ and $C$ ) sagittal T2-weighted MR images obtained before the diagnostic lumbar puncture. Note: Panels $B$ and $C$ are the same images. A and B: Hyperintense areas are seen, extending in the spinal cord from T8 (A) to the conus medullaris (B) (arrowheads in A and B). C: Serpiginous flow voids at L2 and L3 are marked with a dashed line. Before the patient was referred to us, the flow void did not draw clinical attention. Therefore, a diagnostic lumbar puncture was performed after MRI.

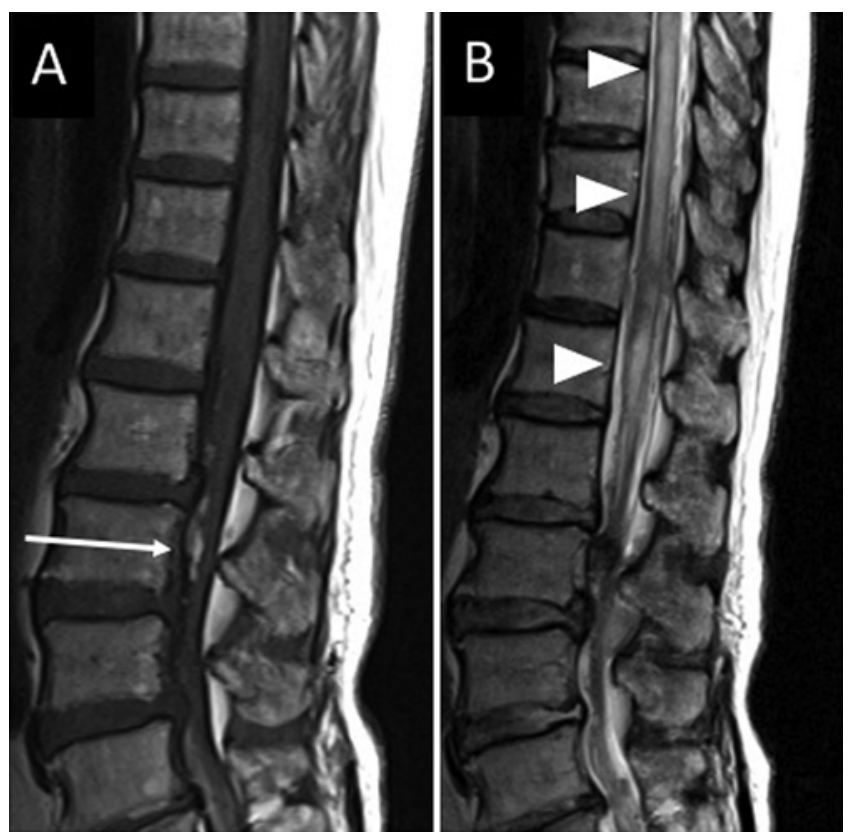

FIG. 2. Thoracolumbar sagittal MR images obtained after the lumbar puncture. A: T1-weighted image showing high-intensity areas, indicating the source of the subarachnoid hemorrhage (arrow). B: T2-weighted image showing hyperintense areas in the spinal cord (arrowheads) that are more apparent at thoracolumbar levels than they had been before the lumbar puncture. mass at the same spinal level. Importantly, the hyperintense spinal cord areas were more intense than they had been on T2-weighted MRI prior to lumbar puncture (Fig. 2). Neurological examination confirmed deterioration of motor and sensory function after lumbar puncture. Three weeks after ictus, the patient could not ambulate and required a walker for assistance. She also required intermittent urinary catheterization for voiding due to new bladder dysfunction following SAH. Before the lumbar puncture, the patient's gait was grade 2 according to the AminoffLogue gait disturbance subscale and micturition function was grade 1 according to the Aminoff-Logue micturition subscale. ${ }^{1}$ Preoperatively, her gait and micturition functions had worsened to grades 4 and 3 , respectively, using the same scale.

Considering spinal vascular lesions in the differential diagnosis, selective spinal angiography was performed. Angiograms obtained from a left L3 injection demonstrated an epidural venous pouch ventral to the dural sac. A perimedullary vein was demonstrated to pierce the dura and ascend intradurally (Fig. 3). On account of the epidural venous pouch as well as an intradural draining vein, SEDAVF at L3 was established as the preoperative diagnosis.

Experienced neurosurgeons (T.E. and T.T.) and neurointerventionalists (K.S. and Y.M.) discussed the treatment options. Since the angiograms demonstrated multiple tor- 

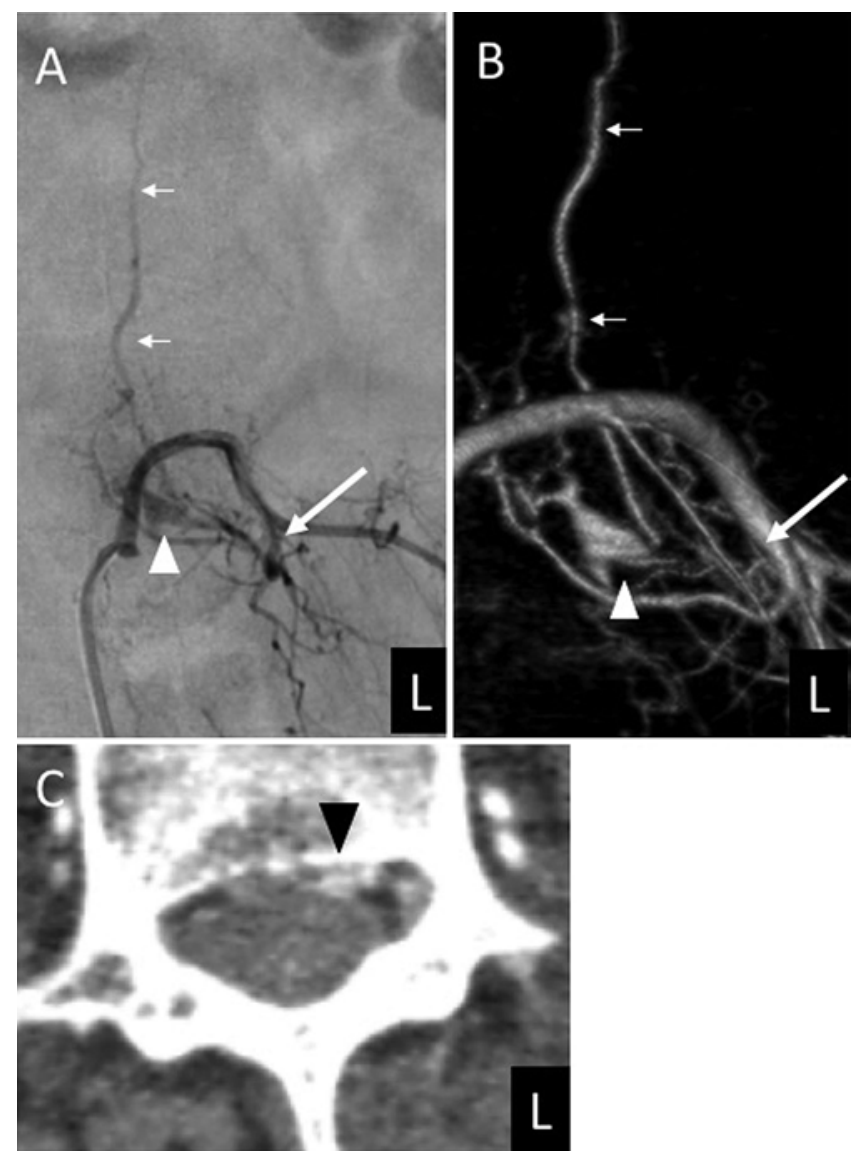

FIG. 3. Selective spinal angiograms of the left $L 3$ segmental artery (A and $B$ ) and axial CT image with contrast (C). A: Anteroposterior view showing the radicular artery as a feeder (large arrow). The epidural venous pouch (arrowhead) and ascending perimedullary vein (small arrows) are seen. B: Three-dimensional reconstructed image showing the angioarchitecture of the lesion. The arrows and arrowhead indicate the same structures as in panel A. C: At the L3 level, ventral to the dural sac, the epidural pouch is seen (arrowhead). In all images, the left side $(\mathrm{L})$ is shown.

tuous feeders contributing to a venous pouch, we considered open surgery as a first choice for this case. Consequently, open surgery was performed 1 month after SAH (Fig. 4). The patient was positioned prone. Following the left L3 hemilaminectomy and durotomy, the enlarged draining vein was obliterated (arrow in Fig. 4). Although we found a remnant of the hematoma (arrowhead in Fig. 4), we could not confirm the source of bleeding. Postoperatively, the patient's gait and sensory disturbance improved remarkably. Six months after surgery, she could ambulate without assistance and did not require catheterization for voiding urine. Aminoff-Logue scale grades improved to 1 in both gait and micturition functions. ${ }^{1}$ Abnormally hyperintense areas and flow voids disappeared on T2-weighted MR images (Fig. 5). The patient was free from recurrence at 5 years after surgical intervention.

\section{Discussion}

In type A SEDAVF, patients often experience combined motor and sensory disturbance as well as blad-

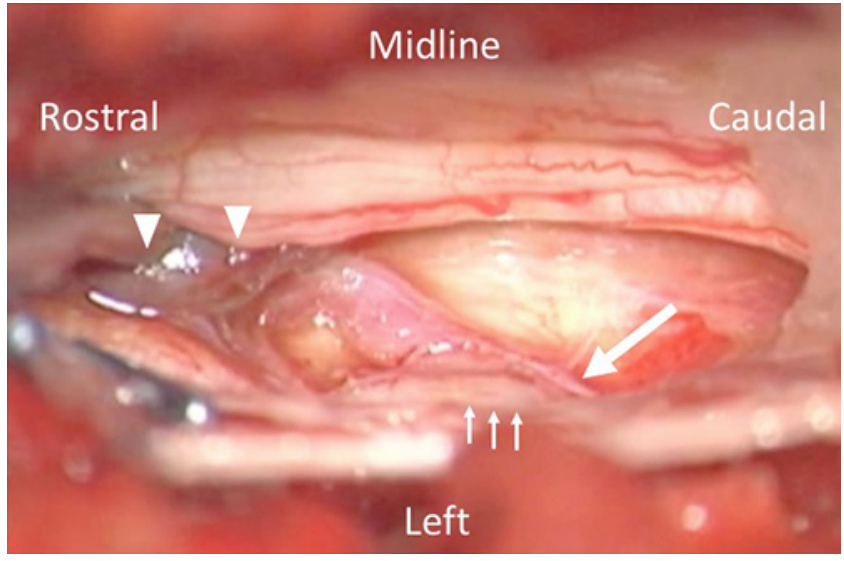

FIG. 4. Intraoperative photograph showing an enlarged draining vein (large arrow), originating from the root sleeve of the left L3. The small arrows indicate the $\mathrm{L} 3$ nerve root. After dissection, a remnant of the hematoma (arrowheads) is seen rostral to the vein. This was where the bleeding occurred after the lumbar puncture. Nonetheless, an exact mechanism leading to the $\mathrm{SAH}$ remained undetermined. Figure is available in color online only.

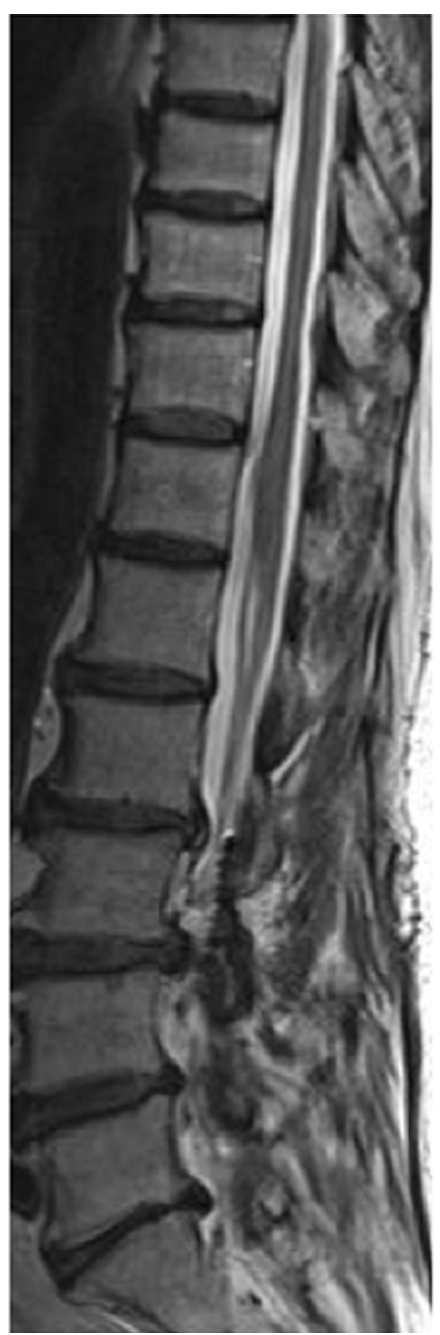

FIG. 5. Thoracolumbar sagittal T2-weighted MR image obtained at 12 months after surgery, confirming the disappearance of flow voids and abnormal intramedullary hyperintense areas. 
TABLE 1. Summary of reported cases of type A SEDAVFs

\begin{tabular}{|c|c|c|c|c|c|}
\hline Authors \& Year & Age (yrs), Sex & Presentation & Location & Pathophysiology & Treatment \\
\hline Arnaud et al., 1994 & $60, M$ & Myelopathy & L2-4 & Venous congestion & TVE \\
\hline \multirow{3}{*}{ Burkhardt et al., 2017} & $60, \mathrm{M}$ & Myelopathy & S1 & Venous congestion & Open surgery \\
\hline & $64, \mathrm{M}$ & Myelopathy & S1 & Venous congestion & Open surgery \\
\hline & $72, \mathrm{M}$ & Myelopathy & S1 & Venous congestion & Open surgery \\
\hline Chul Suh et al., 2004 & $21, \mathrm{~F}$ & Myelopathy & L1-3 & Venous congestion & TVE \\
\hline \multirow{6}{*}{ Clarke et al., 2009} & $70, M$ & Myelopathy & L4 & Venous congestion & TAE \\
\hline & $65, \mathrm{M}$ & Myelopathy & L3-4 & Venous congestion & Open surgery \\
\hline & $61, \mathrm{~F}$ & Calf pain & L3-4 & Venous congestion & Open surgery \\
\hline & $77, \mathrm{M}$ & Myelopathy & L3-4 & Venous congestion & Open surgery \\
\hline & $76, \mathrm{M}$ & Myelopathy & L4-5 & Venous congestion & Open surgery \\
\hline & $53, \mathrm{~F}$ & Myelopathy & L4-S1 & Venous congestion & Open surgery \\
\hline Cognard et al., 1995 & $17, \mathrm{~F}$ & Back pain & T5-L5 & Venous congestion & TAE \\
\hline \multirow{2}{*}{ Goyal et al., 1999} & $73, \mathrm{M}$ & Myelopathy & S1 & Venous congestion & Open surgery \\
\hline & $70, M$ & Myelopathy & $\mathrm{T} 12$ & Venous congestion & Open surgery \\
\hline Kawabori et al., 2009 & $65, \mathrm{~F}$ & Radiculopathy & C5-6 & Mass effect & TAE \\
\hline \multirow{6}{*}{ Kiyosue et al., 2013} & $60, M$ & Myelopathy & L1 & Venous congestion & TVE \& TAE \\
\hline & $60, M$ & Myelopathy & L3 & Venous congestion & TVE \\
\hline & $69, \mathrm{M}$ & Myelopathy & $\mathrm{L} 4$ & Venous congestion & TAE \\
\hline & $73, \mathrm{~F}$ & Myelopathy & $\mathrm{L} 5$ & Venous congestion & TAE \\
\hline & $62, \mathrm{M}$ & Myelopathy & L5 & Venous congestion & TAE \\
\hline & $82, \mathrm{~F}$ & Myelopathy & L2 & Venous congestion & TAE \\
\hline Krings et al., 2006 & $78, \mathrm{M}$ & Myelopathy & L3-4 & Venous congestion & Open surgery \\
\hline Miyamoto et al., 2013 & $55, \mathrm{M}$ & Nuchal pain \& hemiplegia & $\mathrm{C} 3-\mathrm{C} 4$ & Intradural hemorrhage & Open surgery \\
\hline Murakami et al., 2015 & $69, \mathrm{M}$ & Myelopathy & L4 & Venous congestion & TAE \\
\hline \multirow{4}{*}{ Niizuma et al., 2013} & $62, \mathrm{M}$ & Myelopathy & $\mathrm{L} 2$ & Venous congestion & TVE \\
\hline & $51, \mathrm{M}$ & Myelopathy & L3 & Venous congestion & Open surgery \\
\hline & $59, \mathrm{M}$ & Myelopathy & $\mathrm{L} 1$ & Venous congestion & Open surgery \\
\hline & $75, M$ & Myelopathy & $\mathrm{T} 10$ & Venous congestion & Open surgery \\
\hline Pirouzmand et al., 1997 & $72, \mathrm{M}$ & Myelopathy & S1 & Venous congestion & TAE \& open surgery \\
\hline \multirow{4}{*}{$\begin{array}{l}\text { Rangel Castilla et al., } \\
\quad 2011\end{array}$} & $80, M$ & Myelopathy & L5 & Venous congestion & TAE \\
\hline & $72, \mathrm{M}$ & Myelopathy & L2-3 & Venous congestion & TAE \\
\hline & $53, \mathrm{~F}$ & Myelopathy & $\mathrm{T} 12$ & Venous congestion & TAE \\
\hline & $76, M$ & Myelopathy & $\mathrm{L} 1-2$ & Venous congestion & TAE, repeated \\
\hline Reul \& Braun, 2007 & $68, M$ & Myelopathy & L1-2 & Venous congestion & TAE \\
\hline Saito et al., 2007 & $53, \mathrm{~F}$ & Myelopathy & T10-11 & Venous congestion & Open surgery \\
\hline Shankar et al., 2012 & $68, M$ & Myelopathy & T12-L3 & Venous congestion & Open surgery \\
\hline \multirow{3}{*}{ Silva et al., 2007} & $60, \mathrm{~F}$ & Myelopathy & $\mathrm{T} 12$ & Venous congestion & TAE \\
\hline & $68, M$ & Myelopathy & L2-3 & Venous congestion & TAE, repeated \\
\hline & $69, \mathrm{M}$ & Myelopathy & T11-L1 & Venous congestion & TAE \& TVE \\
\hline \multirow{3}{*}{ Vázquez et al., 2017} & $65, M$ & Myelopathy & L4 & Venous congestion & Open surgery \& TAE \\
\hline & $77, \mathrm{M}$ & Myelopathy & L5-S1 & Venous congestion & Open surgery \\
\hline & $42, \mathrm{M}$ & Myelopathy & L5-S1 & Venous congestion & Open surgery \\
\hline Present case & $70, \mathrm{~F}$ & Myelopathy, SAH & L3 & Venous congestion followed by SAH & Open surgery \\
\hline
\end{tabular}

$\mathrm{TAE}=$ transarterial embolization; TVE = transvenous embolization.

der and bowel dysfunction due to congestive myelopathy. $2,5,7-9,12,19,21,23-25,27-30,32-34,36$ Among 42 reported cases of type A SEDAVF (Table 1), only 1 patient, a 55-year-old man, presented with cervical hematomyelia. ${ }^{24}$ Although our patient presented with $\mathrm{SAH}$, it was not considered as a presenting symptom. Rather, the patient originally experienced myelopathy due to venous congestion induced by intradural perimedullary venous drainage, which is a typical presentation of SEDAVF.

Despite lumbar puncture being performed before the 
patient was referred to our hospital, it is essential to speculate as to the reasons why the patient underwent the procedure. When a patient presents with symptoms compatible with myelopathy, MRI is a routine diagnostic examination of choice. Among various differential diagnoses, spinal vascular disease should top of list when T2-weighted MRI indicates intradural signal flow voids along the spinal cord. ${ }^{17}$ However, in this specific case, MRI did not show typical perimedullary flow voids or epidural venous pouches (Fig. 1B). Before the lumbar tap, the tortuous intradural vein did not draw attention at the other hospital. If the serpiginous flow voids had been recognized (dashed line in Fig. 1C), spinal angiography rather than a lumbar tap could have been the next examination. In sacral and lumbar dural AVFs, tortuous intradural veins are a hallmark for prompt diagnosis. ${ }^{6,11}$ It is important to recognize that serpentine signal flow voids in the lumbar spinal canal can also indicate lumbar SEDAVF. Careful lumbar spinal canal inspection on sagittal T2-weighted images is beneficial for prompt diagnosis. ${ }^{13}$

\section{Influence of SAH on Myelopathy}

In the present case, open surgery could not confirm the source of bleeding, leading to the speculation that the needle used in the lumbar puncture may have pierced the enlarged vein or protruded through the dura mater into the venous pouch. When the needle was pulled out, the blood flowed intradurally through the needle track. Importantly, the patient experienced neurological deterioration and incremental T2 hyperintense areas following lumbar puncture. The possibility that SAH induced massive and sudden increments of intradural pressure or venous thrombosis, resulting in worsening venous congestion and spinal cord hypoperfusion, was considered. Lumbar puncture complications include post-lumbar puncture headache, infection, bleeding, and neurological symptoms, such as radial pain or numbness..$^{10,31,37}$ Koerts et al. reported the case of a patient with acute paraplegia after lumbar puncture in the sitting and anteroflexion positions. ${ }^{22}$ The authors speculated that the patient's position during the lumbar puncture caused abdominal compression, which possibly compromised venous return and aggravated spinal cord congestion. ${ }^{14}$

Acute deterioration after epidural injections has also been reported in cases of spinal dural AVF. ${ }^{15}$ After an epidural injection, epidural pressure in the spinal canal increases, which hinders venous return from the arterialized spinal cord venous plexus to the epidural veins. Because the epidural injection could be sufficient for exacerbation of venous hypertension in the spinal cord, it could be understandable that SAH would lead to acute neurological deterioration in a patient with a lumbar SEDAVF.

\section{Treatments for Type A SEDAVF}

For type A SEDAVF, treatment options include open surgery, transarterial embolization, and transvenous embolization (Table 1). ${ }^{2,5,7-9,12,19,21,23-25,27-30,32-34,36}$ For the presented case, we performed open surgery to obliterate the intradural draining vein. As we reported previously, open surgery aiming occlusion at a sole intradural drainer can be used to manage most type A SEDAVFs. ${ }^{27}$ With this strategy, fistulous connections and an epidural venous pouch would theoretically remain. However, a remnant SEDAVF without perimedullary venous reflux would rarely be harmful.

In recent reports, transarterial embolization was more frequently indicated for type A SEDAVFs. ${ }^{20,26}$ According to a multicenter cohort study from Japan, $72.9 \%$ of SEDAVFs were treated with transarterial embolization alone. ${ }^{20}$ It should be an effective approach, with the liquid embolization materials successfully introduced to fill the venous pouch and part of the draining vein. Especially in SEDAVF cases with multiple feeders and a large venous pouch, when transarterial embolization results in incomplete obliteration, a repeated embolization or combined therapies with open surgery would be helpful.

\section{Conclusions}

We experienced a rare case of a lumbar SEDAVF in which a diagnostic lumbar puncture induced severe SAH. Importantly, there are certain SEDAVF cases with typical signal flow voids that are not apparent along the spinal cord. Preoperative evaluation and a high clinical index of suspicion could possibly lead to an appropriate diagnosis and prevent devastating events. Finding a serpiginous vein in the lumbar spinal canal is a key in preoperative MRI.

\section{Acknowledgments}

We thank Enago for the English language review.

\section{References}

1. Aminoff MJ, Logue V: Clinical features of spinal vascular malformations. Brain 97:197-210, 1974

2. Arnaud O, Bille F, Pouget J, Serratrice G, Salamon G: Epidural arteriovenous fistula with perimedullary venous drainage: case report. Neuroradiology 36:490-491, 1994

3. Asai J, Hayashi T, Fujimoto T, Suzuki R: Exclusively epidural arteriovenous fistula in the cervical spine with spinal cord symptoms: case report. Neurosurgery 48:1372-1376, 2001

4. Bradac GB, Simon RS, Schramm J: Cervical epidural AVM. Report of a case of uncommon location. Neuroradiology 14:97-100, 1977

5. Burkhardt JK, Safaee MM, Clark AJ, Lawton MT: Sacral epidural arteriovenous fistulas: imitators of spinal dural arteriovenous fistulas with different pathologic anatomy: report of three cases and review of the literature. Acta Neurochir (Wien) 159:1087-1092, 2017

6. Chen CJ, Hsu HL: Engorged and tortuous intradural filum terminale vein as a sign of a sacral dural arteriovenous malformation. Eur J Radiol 44:152-155, 2002

7. Chul Suh D, Gon Choi C, Bo Sung K, Kim KK, Chul Rhim $\mathrm{S}$ : Spinal osseous epidural arteriovenous fistula with multiple small arterial feeders converging to a round fistular nidus as a target of venous approach. AJNR Am J Neuroradiol 25:69-73, 2004

8. Clarke MJ, Patrick TA, White JB, Cloft HJ, Krauss WE, Lindell EP, et al: Spinal extradural arteriovenous malformations with parenchymal drainage: venous drainage variability and implications in clinical manifestations. Neurosurg Focus 26(1):E5, 2009

9. Cognard C, Semaan H, Bakchine S, Miaux Y, Thibault S, Sola Martinez MT, et al: Paraspinal arteriovenous fistula with perimedullary venous drainage. AJNR Am J Neuroradiol 16:2044-2048, 1995 
10. Doherty CM, Forbes RB: Diagnostic lumbar puncture. Ulster Med J 83:93-102, 2014

11. Endo T, Kajitani T, Inoue T, Sato K, Niizuma K, Endo H, et al: Clinical characteristics of lumbosacral spinal dural arteriovenous fistula (DAVF)-comparison to thoracic DAVF World Neurosurg 110:e383-e388, 2018

12. Goyal M, Willinsky R, Montanera W, terBrugge K: Paravertebral arteriovenous malformations with epidural drainage: clinical spectrum, imaging features, and results of treatment. AJNR Am J Neuroradiol 20:749-755, 1999

13. Haryu S, Endo T, Sato K, Inoue T, Takahashi A, Tominaga T: Cognard type V intracranial dural arteriovenous shunt: case reports and literature review with special consideration of the pattern of spinal venous drainage. Neurosurgery 74:E135E142, 2014

14. Hassler W, Thron A: Flow velocity and pressure measurements in spinal dural arteriovenous fistulas. Neurosurg Rev 17:29-36, 1994

15. Hetts SW, Narvid J, Singh T, Meagher S, Corcoran K, Higashida RT, et al: Association between lumbar epidural injection and development of acute paraparesis in patients with spinal dural arteriovenous fistulas. AJNR Am J Neuroradiol 28:581-583, 2007

16. Huang W, Gross BA, Du R: Spinal extradural arteriovenous fistulas: clinical article. J Neurosurg Spine 19:582-590, 2013

17. Hurst RW, Kenyon LC, Lavi E, Raps EC, Marcotte P: Spinal dural arteriovenous fistula: the pathology of venous hypertensive myelopathy. Neurology 45:1309-1313, 1995

18. Johnson CE, Russell EJ, Huckman MS: Resolution of spinal epidural vascular pseudotumor following balloon occlusion of a postoperative vertebral arteriovenous fistula. Neuroradiology 31:529-532, 1990

19. Kawabori M, Hida K, Yano S, Asano T, Iwasaki Y: Cervical epidural arteriovenous fistula with radiculopathy mimicking cervical spondylosis. Neurol Med Chir (Tokyo) 49:108-113, 2009

20. Kiyosue H, Matsumaru Y, Niimi Y, Takai K, Ishiguro T, Hiramatsu $\mathrm{M}$, et al: Angiographic and clinical characteristics of thoracolumbar spinal epidural and dural arteriovenous fistulas. Stroke 48:3215-3222, 2017

21. Kiyosue H, Tanoue S, Okahara M, Hori Y, Kashiwagi J, Mori H: Spinal ventral epidural arteriovenous fistulas of the lumbar spine: angioarchitecture and endovascular treatment. Neuroradiology 55:327-336, 2013

22. Koerts G, Vanthuyne V, Delavallee M, Rooijakkers H, Raftopoulos C: Spinal dural arteriovenous fistula presenting with paraplegia following lumbar puncture. J Neurosurg Spine 19:57-60, 2013

23. Krings T, Mull M, Bostroem A, Otto J, Hans FJ, Thron A: Spinal epidural arteriovenous fistula with perimedullary drainage. Case report and pathomechanical considerations. J Neurosurg Spine 5:353-358, 2006

24. Miyamoto N, Naito I, Takatama S, Iwai T, Tomizawa S, Inoue HK: Spinal epidural arteriovenous fistulas with unusual manifestation of sudden onset of severe neurological deficits: case report. Neurol Med Chir (Tokyo) 53:896-901, 2013

25. Murakami T, Nakagawa I, Wada T, Kichikawa K, Nakase H: Lumbar spinal epidural arteriovenous fistula with perimedullary venous drainage after endoscopic lumbar surgery. Interv Neuroradiol 21:249-254, 2015

26. Nasr DM, Brinjikji W, Clarke MJ, Lanzino G: Clinical presentation and treatment outcomes of spinal epidural arteriovenous fistulas. J Neurosurg Spine 26:613-620, 2017

27. Niizuma K, Endo T, Sato K, Takada S, Sugawara T, Mikawa
S, et al: Surgical treatment of spinal extradural arteriovenous fistula with parenchymal drainage: report on 5 cases. Neurosurgery 73 (2 Suppl Operative):E287-E294, 2013

28. Pirouzmand F, Wallace MC, Willinsky R: Spinal epidural arteriovenous fistula with intramedullary reflux. Case report. J Neurosurg 87:633-635, 1997

29. Rangel-Castilla L, Holman PJ, Krishna C, Trask TW, Klucznik RP, Diaz OM: Spinal extradural arteriovenous fistulas: a clinical and radiological description of different types and their novel treatment with Onyx. J Neurosurg Spine 15:541549,2011

30. Reul J, Braun V: Spinal arteriovenous epidural fistula with acute paraplegia. Diagnosis and neurointerventional emergency treatment. A case report. Interv Neuroradiol 13:7578, 2007

31. Ruff RL, Dougherty JH Jr: Complications of lumbar puncture followed by anticoagulation. Stroke 12:879-881, 1981

32. Saito A, Takahashi T, Ezura M, Tominaga T: Intercostal arteriovenous fistula associated with neurofibromatosis manifesting as congestive myelopathy: case report. Neurosurgery 61:E656-E657, 2007

33. Shankar JJ, terBrugge K, Krings T: Spinal epidural arteriovenous fistula with double perimedullary reflux. Can J Neurol Sci 39:239-241, 2012

34. Silva N Jr, Januel AC, Tall P, Cognard C: Spinal epidural arteriovenous fistulas associated with progressive myelopathy. Report of four cases. J Neurosurg Spine 6:552-558, 2007

35. Takai K, Taniguchi M: Comparative analysis of spinal extradural arteriovenous fistulas with or without intradural venous drainage: a systematic literature review. Neurosurg Focus 32(5): $\mathrm{E} 8,2012$

36. Vázquez EJ, Gefaell J, Fernandez L, López E, Areitio E, Elexpuru JA: Spinal extradural arteriovenous fistula with intradural drainage: three surgical cases with long-term follow-up. Acta Neurochir (Wien) 159:1107-1111, 2017

37. Williams J, Lye DC, Umapathi T: Diagnostic lumbar puncture: minimizing complications. Intern Med J 38:587-591, 2008

38. Willinsky R, terBrugge K, Montanera W, Wallace MC, Gentili F: Spinal epidural arteriovenous fistulas: arterial and venous approaches to embolization. AJNR Am J Neuroradiol 14:812-817, 1993

\section{Disclosures}

The authors report no conflict of interest concerning the materials or methods used in this study or the findings specified in this paper.

\section{Author Contributions}

Conception and design: Endo, Kajitani, Tominaga. Acquisition of data: Endo, Kajitani, Inoue, Sato, Matsumoto. Analysis and interpretation of data: Endo. Drafting the article: Endo, Kajitani, Inoue. Critically revising the article: Sato, Matsumoto, Tominaga. Reviewed submitted version of manuscript: all authors. Approved the final version of the manuscript on behalf of all authors: Endo. Administrative/technical/material support: Matsumoto. Study supervision: Endo, Tominaga.

\section{Correspondence}

Toshiki Endo: Kohnan Hospital, Sendai, Japan. endo@nsg.med. tohoku.ac.jp. 